\title{
Priporočila za oceno in obravnavo stridorja pri otroku
}

\section{Recommendations for the assessment and management of stridor in children}

Petra Pavlič, Ana Kotnik Pirš

\section{Izvleček}

Stridor je visokofrekvenčen zvok, ki nastane zaradi nihanja zraka ob zoženih večjih dihalnih poteh. Slišimo ga s prostim ušesom. Lahko je znak funkcionalno nepomembnega stanja, lahko pa je posledica življenje ogrožajočega stanja, ki zahteva takojšnjo prepoznavo in obravnavo. Epidemioloških podatkov o stridorju je malo, vzrokov zanj veliko. $V$ večini literature stridor razvrščajo glede na vzrok in glede na anatomsko mesto zožitve dihalne poti. Ker smo prispevek pripravili predvsem za hitro in pregledno uporabnost v klinični praksi, smo stridor razdelili glede na klinično sliko in izdelali diagnostični algoritem za obravnavo otroka s stridorjem.

Ključne besede: stridor, otrok, obravnava.

\begin{abstract}
Stridor describes a high-pitched sound that is caused by the oscillation of air through the narrowed large airways. It can be heard without a stethoscope. It may be a sign of a functionally insignificant condition, or it may be the result of a life-threatening condition that requires immediate recognition and treatment. There is a lack of epidemiological data on stridor, for which there are a variety of causes. In most of the literature, stridor is divided according to the cause and the anatomical site of the airway narrowing. The purpose of this article is to provide quick and clear applicability to clinical practice. We divided variations in stridor according to the clinical picture and formulated a diagnostic algorithm for the management of the child with stridor.
\end{abstract}

Key words: stridor, child, management. 


\section{Uvod}

Stridor je visokofrekvenčen zvok, ki nastane med dihanjem zaradi nihanja zraka ob delni zapori večjih dihalnih poti v predelu nosu, žrela, grla, sapnika ali glavnih bronhov. Navadno ga slišimo brez stetoskopa. Razlikovati ga moramo od piskanja (angl. wheezing), ki je polifon zvok, navadno slišen le s stetoskopom, in nastane zaradi zožitve dihalnih poti distalno od proksimalne sapnice, in stertorja, ki je nizkofrekvenčen zvok, podoben smrčanju, in nastane ob obstrukciji nosu ali žrela (1).

Najpogosteje je stridor slišen med vdihom (inspiratorni stridor), lahko pa je slišen tudi med izdihom (ekspiratorni stridor) ali v obeh fazah dihanja (bifazni stridor). Vzroki stridorja so različni, v osnovi pa jih razdelimo na prirojene in pridobljene. Glede na čas nastanka razlikujemo med akutnim stridorjem in kroničnim stridorjem $(2,3)$.

Glede na stopnjo obstrukcije dihalne poti gre lahko za funkcionalno nepomembno stanje ali za življenje ogrožajoče stanje, ki zahteva takojšnjo obravnavo (4).

\section{Epidemiologija}

Stridor je simptom zožitve dihalne poti. Vzroki so različni, zato natančne pogostosti ne poznamo. Najpogostejši vzrok stridorja v prvih mesecih življenja je laringomalacija. Kronični stridor je $v$ večini posledica prirojene nepravilnosti $v$ dihalni poti. Najpogostejši vzrok stridorja zaradi pridobljenih vzrokov pri malčkih je akutni laringotraheitis ali krup (3).

\section{Etiopatofiziologija stridorja}

Nastanek stridorja lahko razložimo z uporabo Bernoullijeve enačbe in Poiseuillovega zakona, prilagojenima za uporabo na primeru dihalnih poti. Pri zožitvi dihalne poti pride zaradi zmanjšanja premera dihalne poti do poveča- nega upora v dihalnih poteh, saj je upor obratno sorazmeren s četrto potenco polmera dihalne poti (Poiseuillov zakon). Zaradi zmanjšanega preseka dihalne poti na teh odsekih se poveča hitrost pretoka zraka, tlak pa se zmanjša (Bernoullijeva enačba). Ob zmanjšanem tlaku $v$ dihalnih poteh pride do njihovega kolapsa in turbulentnega toka, $\mathrm{ki}$ povzroči vibracijo tkiv in s tem stridor (2).

\section{Stridor glede na fazo dihanja}

Glede na fazo dihanja, v kateri se stridor pojavi, razlikujemo inspiratorni stridor, ekspiratorni stridor in bifazni stridor.

- Inspiratorni stridor se pojavi predvsem pri zožitvi dihalne poti zunaj prsnega koša. Supraglotično področje je pri dojenčku v obliki lijaka in obdano z mehkimi tkivi, ki so premakljiva. Do stridorja pride zaradi sesedanja mehkih struktur med vdihom, medtem ko se med izdihom mehke strukture razmaknejo, zato sesedanja dihalne poti ni. Najpogostejši vzrok prirojenega stridorja pri dojenčkih je laringomalacija. S starostjo pri otroku laringomalacija večinoma izzveni, stanje pa se lahko ob akutnih okužbah prehodno poslabša. Takrat se izrazijo znaki akutnega laringitisa $(2,5,6)$.

- Ekspiratorni stridor je prisoten pri bolezenskih spremembah $v$ področju intratorakalnega predela dihalne poti od proksimalnega dela sapnika navzdol, saj se spodnji del sapnice med vdihom zaradi negativnega tlaka v prsni votlini razširi, med izdihom pa je tlak $v$ prsnem košu pozitiven in lahko pride do sesedanja dihalne poti. Pogost vzrok je traheomalacija (7).

- Bifazni stridor je posledica nespremenljive zapore dihalne poti ali pomembne zožitve svetline dihalne poti ne glede na mesto zapore. Povzročajo ga lahko pritisk od zunaj, mase v svetlini dihalne poti (tujek, hemangiom) ali spremembe sluznice, kot je subglotisna zožitev (2).
Stridor glede na čas nastanka

Poznamo akutni stridor in kronični stridor.

Akutni stridor se razvije v nekaj minutah do urah in lahko hitro napreduje. Predvsem je posledica pridobljenih vzrokov, zlasti okužb oziroma vnetnih procesov, lahko pa je posledica opekline, anafilaksije ali aspiracije tujka (1).

- Aspiracija tujka je stanje, na katerega vedno pomislimo pri dojenčku ali malčku. Prisotna je lahko dihalna stiska. Najvišja pojavnost je v starostni skupini med 2. in 3. letom. Pomembna je skrbna heteroanamneza o okoliščinah, ko se je stridor začel, ali so bili vidni znaki aspiracije in kašelj oziroma ali so priče videle aspiracijo tujka (8).

- Anafilaksija je pogosto in življenje ogrožajoče stanje. Pomemben je podatek o morebitnem stiku z alergenom. V kliničnem pregledu lahko ugotavljamo spremembe v glasu, davljenje, piskanje, kašelj ali slinjenje. Prav tako so lahko prisotne spremembe po koži, kot so izpuščaj, srbečica in zatekanje mehkih tkiv, ter gastrointestinalni simptomi, na primer slabost, bruhanje, driska ali bolečine $v$ trebuhu (9).

- Subglotisni laringitis oziroma akutni laringotraheitis ali krup je najpogostejši vzrok akutnega stridorja pri otrocih. Gre za vnetje in oteklino subglotisnega področja dihalne poti, najpogostejši povzročitelji pa so virusi. Pojavlja se predvsem pri otrocih med 6. mesecem in 3. letom starosti. Otroci imajo hripav glas, lajajoč kašelj in stridor, lahko je prisotno tudi težko dihanje, ki se kaže z ugrezanjem mehkih delov prsnega koša. Težave se pojavljajo predvsem ponoči. Večinoma poteka $v$ blagi obliki in ne zahteva posebnega zdravljenja, le počitek, zadostno uživanje tekočin in po potrebi antipiretik, v primeru težkega dihanja pa glukokortikoid in inhalacije adrenalina (10).

- Epiglotitis je redko, a življenje ogrožajoče stanje. Po uvedbi cepljenja proti bakteriji Haemophilus influen- 
zae tipa B se je njegova pojavnost zelo znižala. Vrh pojavnosti je po sedmem letu starosti. Začne se nenadno $z$ visoko vročino, otrok ima zamolkel glas, se obilno slini in je videti prizadet. Zavzame značilen položaj - v sedečem položaju se nagne naprej, izravna vrat, ima odprta usta in jezik izplazi naprej $(11,12)$.

\section{- Bakterijski traheitis oziroma psev-} domembranozni krup je redek in se najpogosteje pojavi pri otrocih do šestega leta. Virusni okužbi sledi sekundarna okužba, najpogosteje z bakterijo Staphylococcus aureus. Otrok ima sprva prehladne znake, po nekaj dneh pa se pojavita visoka vročina in splošna prizadetost. Okužba povzroči membranozno vnetje sluznice in s tem zožitev dihalne poti. Je življenje ogrožajoče stanje, ki zahteva hitro obravnavo in takojšnje ukrepanje, najpogosteje hospitalizacijo na intenzivnem oddelku, ter zdravljenje s parenteralnimi antibiotiki. Na bakterijski traheitis pogosto posumimo, če se krup ne odziva na standardno zdravljenje (13).

- Opekline dihalne poti (kavstične ali termalne) se kažejo podobno kot infekcijski epiglotitis in so nujno stanje (14).

Kronični stridor je največkrat posledica strukturne nepravilnosti, ki je najpogosteje prirojena, lahko pa tudi pridobljena. Stridor zaradi prirojene nepravilnosti je lahko prisoten že od rojstva, lahko pa se razvije $v$ dneh, tednih ali mesecih $(1,3)$. Pojavi se lahko tudi pri gastroezofagealnem refluksu (15).

- Laringomalacija je najpogostejši vzrok stridorja pri novorojenčkih (60-70 \%). Gre za sesedanje supraglotičnih struktur med vdihom. Tipično se stridor pojavi v nekaj tednih po rojstvu in izzveni med 12. in 18. mesecem starosti. Prisoten je inspiratorni stridor, ki je bolj izrazit v ležečem položaju ter med hranjenjem, jokom in spanjem, prehodno pa se poslabša tudi ob prebolevanju akutnih okužb dihal (16). Na Sliki 1 prikazujemo bronhoskopski posnetek normalnega grla otroka, na Sliki 2 pa grla otroka z laringomalacijo.

- Pareza glasilk je drugi najpogostejši razlog kroničnega stridorja. Enostranska paraliza je lahko prirojena ali posledica poškodbe pri rojstvu ali operativnem posegu. Stridor je pri enostranski paralizi bifazni, otroci šibko jokajo. Pri obojestranski paralizi glasilk je glas navadno dober.

- Subglotisna zožitev je lahko pridobljena, kar je najpogosteje posledica dolgotrajne in travmatske intubacije, ali pa je prirojena.

- Med redkejše kronične vzroke stridorja uvrščamo tudi traheomalacijo, prirojeno zožitev sapnika ali zožitev sapnika zaradi pritiska "od zunaj" (npr. anomalni potek velikih žil oziroma žilni obroč okrog dihalne poti), infantilne hemangiome (Slika 3), z naporom izzvano obstrukcijo grla (angl. exercise induced laryngeal obstruction, EILO), traheoezofagealno fistulo, tumorje ali prizadetost grlnega živca (n. laryngeus reccurens) $(3,17)$.

\section{Diagnostični algoritem in obravnava otroka s stridorjem}

Vzroki stridorja se razlikujejo glede na starost otroka ter čas nastanka in naravo stridorja (inspiratorni, ekspiratorni ali bifazni). Zato sta potrebna natančna anamneza in klinični pregled, s katerima ocenimo, ali gre za stridor ali ne, resnost stridorja oziroma zapore dihal in s tem potrebo po nujni zagotovitvi proste dihalne poti in dihalne podpore ter morebitne dodatne simptome in znake. To nas vodi $\mathrm{k}$ najverjetnejši diferencialni diagnozi, odločitvi o dodatnih diagnostičnih preiskavah in potrebi po nadaljnji napotitvi otroka k specialistu pulmologu ali otorinolaringologu na nadaljnjo diagnosticiranje in zdravljenje (18). Algoritem obravnave otroka s stridorjem na primarni ravni prikazujemo na Sliki 4.
Pri obravnavi otroka s stridorjem najprej ocenimo stanje zavesti, prehodnost otrokove dihalne poti, učinkovitost dihanja in znake sistemske prizadetosti. Oceniti moramo življenjske znake, hitrost in globino dihanja, dihalni napor, morebitne dihalne premore, cianozo in hipoksijo $(2,18)$.

V primeru hemodinamske nestabilnosti moramo zagotoviti prehodnost dihalne poti $z$ endotrahealno intubacijo ali kirurško vzpostavitvijo dihalne poti in začeti z ukrepi za stabilizacijo otroka. Pri akutnem stridorju sta hipoksemija in hiperkapnija redki, a sta opozorilna znaka, ki zahtevata takojšnje ukrepanje (18).

Če je otrok hemodinamsko stabilen, sta pomembna natančna anamneza in klinični pregled, nato pa sledi odločitev o morebitnih dodatnih diagnostičnih postopkih. Zlasti se poslužujemo laboratorijskih testov, radioloških preiskav, testov pljučne funkcije in endoskopije (2).

\section{Anamneza}

Številni starši obiščejo pediatra zaradi "glasnega dihanja" oziroma piskanja. Ugotoviti moramo, ali gre za stridor ali morda za drug zvočni fenomen, na primer stertor (19).

Pomembna je otrokova starost, saj se nekateri vzroki stridorja pojavljajo v določenih starostnih obdobjih. Pri novorojenčkih in dojenčkih so najpogostejši prirojeni vzroki, zlasti laringomalacija (17). Med malčki je najpogostejši krup, pogoste pa so tudi aspiracije tujka. Redka, a življenje ogrožajoča sta epiglotitis in traheitis. Vzroki stridorja pri šolarjih in adolescentih so zlasti peritonzilarni abscesi in disfunkcija glasilk. Anafilaksija se pojavlja v vseh starostnih obdobjih (3).

Povprašati moramo tudi o času in hitrosti nastanka stridorja; ali je stridor nastal akutno ali kronično, se s časom poslabšuje ali izboljšuje in kaj je otrok počel ob pojavu stridorja oziroma pred pojavom stridorja. Hitronastali in napredu- 


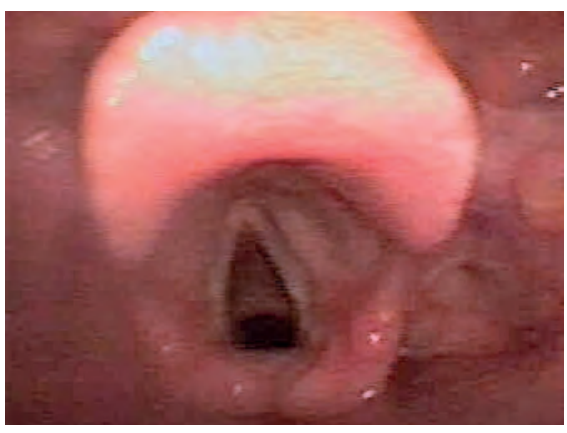

SLIKA 1. BRONHOSKOPSKI POSNETEK NORMALNEGA GRLA OTROKA

FIGURE 1. BRONCHOSCOPIC IMAGE OF A NORMAL LARYNX OF A SMALL CHILD.

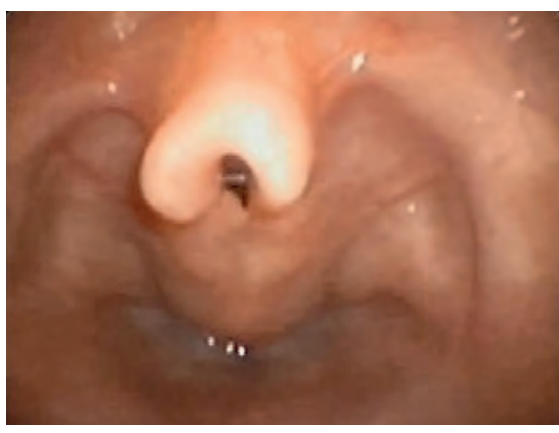

SLIKA 2. BRONHOSKOPSKI POSNETEK GRLA DOJENČKA Z LARINGOMALACIJO.

FIGURE 2. BRONCHOSCOPIC IMAGE IN AN INFANT WITH LARYNGOMALACIA.

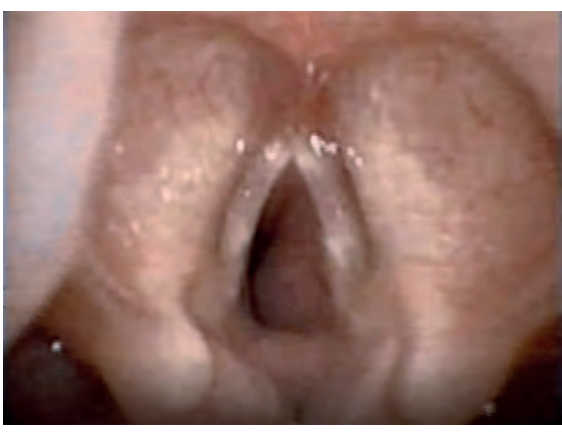

SLIKA 3. BRONHOSKOPSKI POSNETEK GRLA DOJENČKA S SUBGLOTISNO ZOŽITVIJO ZARADI HEMANGIOMA.

FIGURE 3. BRONCHOSCOPIC IMAGE OF A BABY WITH SUBGLOTTIC STENOSIS DUE TO A HAEMANGIOMA.

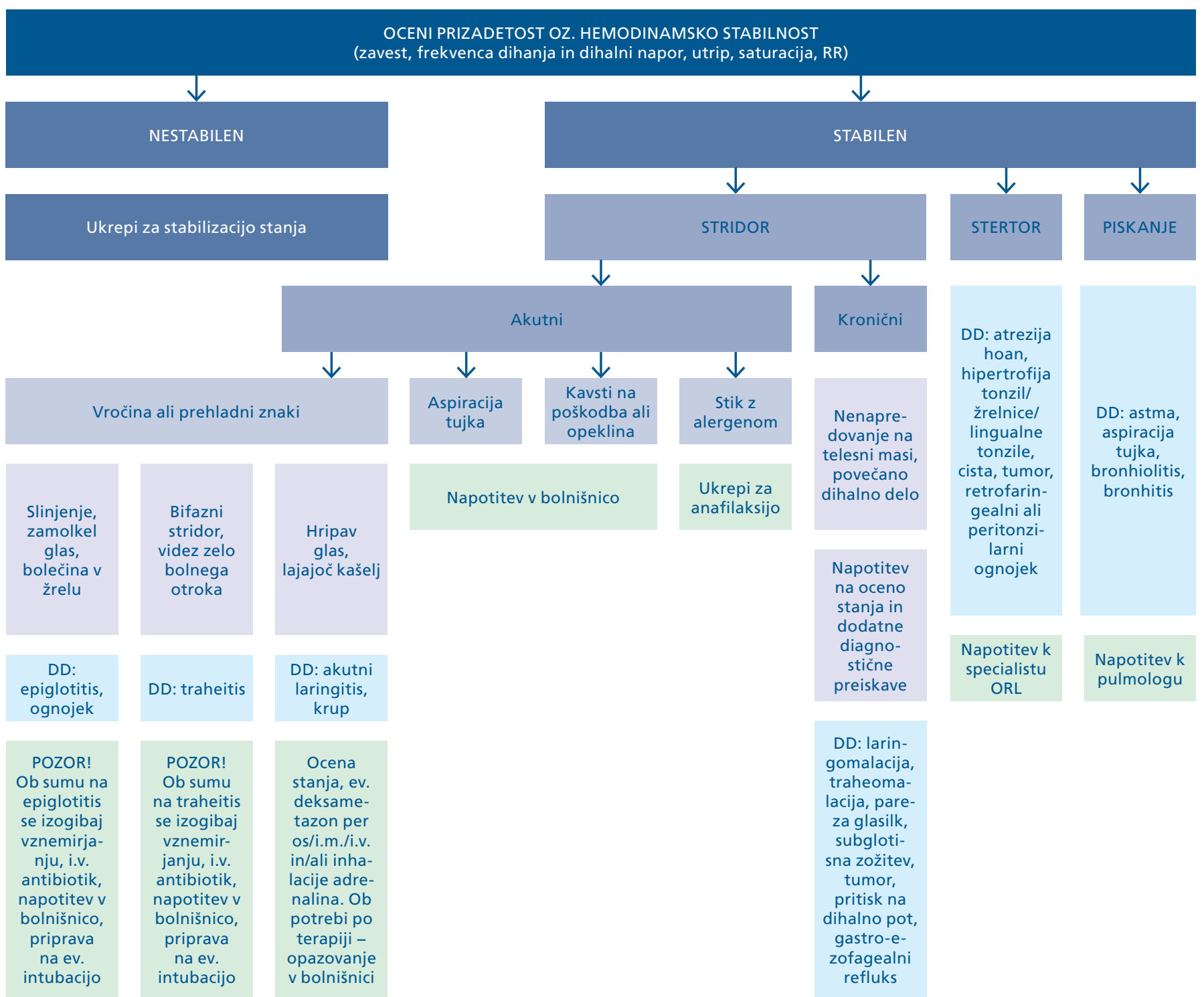

SLIKA 4. ALGORITEM OBRAVNAVE OTROKA S STRIDORJEM V PRIMARNI AMBULANTI.
FIGURE 4. ALGORITHM FOR THE MANAGEMENT OF A CHILD WITH STRIDOR IN THE PRIMARY CARE SETTING. 
joči stridor je lahko znak epiglotitisa ali traheitisa, zlasti ob prisotnosti povišane telesne temperature in znakov sistemske prizadetosti. Prav tako moramo pomisliti na anafilaksijo in aspiracijo tujka. Nekoliko počasnejši potek pričakujemo pri krupu. Peritonzilarni in retrofaringealni absces se navadno razvijeta po simptomih tonzilitisa oziroma faringitisa. Dalj časa trajajoči stridor je navadno posledica prirojenega ali neinfekcijskega pridobljenega vzroka. Pozanimamo se tudi, ali je se stridor s časom spreminja in ali je nastal po določenem dogodku, na primer po intubaciji. Nenadne intermitentne epizode stridorja so značilne za disfunkcijo glasilk (20).

Vprašamo tudi o dejavnikih, ki izboljšajo oziroma poslabšajo stridor oziroma ob katerih se stridor pojavi: odvisnost od telesnega položaja, spanja, joka, vznemirjenosti in hranjenja, kar omogoča določitev mesta zožitve dihalne poti. Starše vprašamo, ali se otrok med hranjenjem utruja ter kako pridobiva na telesni masi in višini. Pomembna zožitev dihalne poti lahko namreč poveča dihalno delo in $\mathrm{s}$ tem porabo kalorij, kar vodi v nepridobivanje telesne mase in rasti. Polivanje in regurgitacija sta znaka gastroezofagealnega refluksa, ki povzroča draženje dihalne sluznice in posledično edem.

Pomemben je tudi podatek o morebitnem pomodrevanju in dihalnih premorih.

Zanimajo nas tudi morebitni pridruženi simptomi: vročina, ki je navadno visoka predvsem pri bakterijskih okužbah in nekoliko nižja pri krupu. Slinjenje in zamolkel glas se pojavita pri supraglotičnih patologijah (pri epiglotitisu in retrofaringealnem abscesu), prav tako se lahko otrok slini po aspiraciji tujka ali masi, ki pritiska na steno požiralnika. Povprašamo tudi o kašlju; lajajoč kašelj je prisoten pri krupu. Težave pri požiranju lahko nakazujejo na stridor, ki je posledica "pritiska od zunaj".

$\checkmark$ antenatalni, perinatalni, postnatalni in dotedanji anamnezi sprašujemo predvsem o tipu poroda in morebitnem izpahu ramen, potrebi po oživljanju ter invazivni dihalni podpori in njenem trajanju. Zanimajo nas tudi morebitne operacije, zlasti v predelu glave, vratu in prsnega koša, pri katerih bi lahko prišlo do poškodbe povratnega grlnega živca. Pomemben je podatek o drugih boleznih, zlasti pljučnih, srčnih, nevroloških in hemato-onkoloških.

Vprašamo tudi o morebitnih alergijah in stiku z alergeni, infekcijskimi agensi, kavstičnimi snovmi ali vročimi tekočinami oziroma plinom $(3,20)$.

\section{Klinični pregled}

Pri hemodinamsko stabilnem otroku nadaljujemo $z$ natančnim kliničnim pregledom po organskih sistemih. Pozorni smo na fazo dihanja, $v$ kateri se stridor pojavlja, saj s tem dobimo podatek o najverjetnejšem mestu in o resnosti zožitve dihalne poti. Pozorni smo tudi na položaj, ki ga otrok zavzame, da si olajša dihanje. Pozorni smo na morebitne sindromske značilnosti, saj so nekateri sindromi povezani s patologijami dihalne poti (na primer trisomija 21 in sindrom CHARGE) (2).

Izmerimo otrokovo višino in telesno maso ter ju primerjamo s predhodnimi vrednostmi, če so na voljo. Pregledamo kožo, bezgavke in ude ter iščemo morebitne izpuščaje in otekanje mehkih tkiv, ki bi bili lahko posledica anafilaktične reakcije. Kožni hemangiomi so v polovici primerov povezani s subglotisnimi hemangiomi $(3,5)$. Iščemo morebitne brazgotine po operacijah. Betičasti prsti lahko nakazujejo pljučne ali srčne bolezni.

Pozorni smo tudi na otrokov glas oziroma jok in slinjenje. Hripavost je značilna za bolezni, ki prizadenejo grlo, kot sta enostranska paraliza glasilk in krup. Pri otroku s sumom na epiglotitis je potrebna previdna manipulacija v predelu žrela, saj lahko pride do akutne zapore dihalne poti.

Pogledamo oči, ušesa, nos, žrelo in vrat. Iščemo morebiten izcedek iz nosu. Edem vratu in vročina se lahko pojavita pri retrofaringealnem ali peritonzilarnem ognojku.
Sledi pregled pljuč in srca. Ponovno smo pozorni na znake povečanega dihalnega dela in cianozo. Pozorno avskultiramo pljuča in srce in iščemo morebitne dodatne zvočne fenomene, kot so srčni šumi, ki so lahko posledica srčnih napak $(1,3,20)$.

\section{Diagnostične preiskave}

- Laboratorijske preiskave vključujejo kompletno krvno sliko ob sumu na infekcijski vzrok in po potrebi hitri panel za dokaz virusov. Pri tipični klinični sliki krupa laboratorijski testi niso potrebni (3).

- Radiološke preiskave uporabljamo predvsem pri atipičnem ali težkem poteku krupa, ob sumu na retrofarineaglni ognojek, epiglotitis, traheitis in ob sumu na aspiracijo tujka. Lateralni rentgenski posnetek vratu uporabljamo za oceno retrofaringealnega prostora ob sumu na absces $v$ tem prostoru oziroma ob sumu na epiglotitis, pri čemer smo pozorni na t. i. znak palca, ki je posledica zadebeljenega epiglotisa. Anterioposterialna projekcija vratu lahko pokaže značilno subglotisno zožitev pri krupu, ki jo imenujemo znak zvonca (angl. steeple sign), a rentgensko slikanje pri tipični klinični sliki krupa ni potrebno. Pri sumu na aspiracijo tujka opravimo rentgensko slikanje prsnega koša, in sicer med vdihom in izdihom. Iščemo radiopačne tujke ali posredne znake aspiracije tujka. Rentgensko slikanje prsnega koša lahko pokaže tudi nekatere anomalije srca in žil ter povečane mediastinalne bezgavke, ki lahko pritiskajo na dihalno pot. Pri sumu na bakterijski traheitis naredimo lateralni in anteroposteriorni posnetek prsnega koša, na katerih lahko vidimo subglotisno zožitev (18). CT vratu in prsnega koša se poslužujemo pri stabilnem bolniku ob sumu na "pritisk od zunaj" ali takrat, ko vzroka za stridor ne moremo opredeliti $z$ drugimi preiskavami (21). Magnetnoresonančno slikanje je uporabno predvsem za diagnosticiranje zožitve sapnika (22). 
- Teste pljučne funkcije oziroma spirometrijo uporabljamo pri otrocih z blagim kroničnim stridorjem, ki so dovolj stari, da lahko dobro sodelujejo, kar je navadno po šestem letu starosti. Oblika krivulje pretok-volumen omogoča razlikovanje mesta zoženja dihalne poti in spremenljivosti zoženja in je pomembna predvsem pri diagnosticiranju z naporom sprožene zapore grla (angl. exercise-induced laryngeal obstruction, EILO) (23).

- Endoskopske preiskave z fleksibilnim (upogibljivim) ali rigidnim (togim) fiberoptičnim inštrumentom omogočajo neposreden prikaz dihalne poti in s tem postavitev dokončne diagnoze (18). Rigidne bronhoskopije, ki zahteva splošno anestezijo, se poslužujemo pri sumu na aspiracijo tujka (24), fleksibilna bronhoskopija pa omogoča preiskavo tudi v blagi anesteziji, ki posnema spanje, in nudi prikaz dinamičnih sprememb $v$ dihalni poti med spontanim dihanjem (25).

Vsakega otroka s kroničnim stridorjem moramo napotiti na nadaljnjo obravnavo k specialistu otorinolaringologu ali specialistu pediatričnemu pulmologu, ki je izkušen v endoskopiji dihalne poti. Prav tako je napotitev potrebna pri otrocih $z$ akutnim stridorjem $s$ sumom na aspiracijo tujka ali z infekcijskim vzrokom stridorja, ki se ne odziva na zdravljenje, oziroma stridor traja več kot 14 dni (18).

\section{Zaključek}

Stridor je znak zoženja večjih dihalnih poti. Vzrokov zanj je veliko. Lahko so benigni, lahko pa kažejo na življenje ogrožajoče stanje, ki zahteva hitro prepoznanje in takojšnje ukrepanje. Akutni stridor pri otrocih je navadno posledica infekcijskih vzrokov, kronični pa prirojenih vzrokov, najpogosteje laringomalacije. Pri kroničnem stridorju je bistveno, da ocenimo, ali otrok pridobiva na telesni masi in ali se ob hranjenju utruja. S pomočjo dia- gnostičnega algoritma, ki ga predstavljamo v prispevku, želimo zdravnikom $v$ primarnih ambulantah ob natančni anamnezi in kliničnemu pregledu olajšati odločitev o nadaljnji obravnavi otroka s stridorjem.

\section{Literatura}

1. Boudewyns A, Claes J, Van De Heyning P. Clinical practice : An approach to stridor in infants and children. Vol. 169, European Journal of Pediatrics 2010: 135-41.

2. Ida JB, Thompson DM. Pediatric Stridor. Vol. 47, Otolaryngologic Clinics of North America. W.B. Saunders; 2014. str. 795-819.

3. Pfleger A, Eber E. Assessment and causes of stridor. Vol. 18, Paediatric Respiratory Reviews. W.B. Saunders Ltd; 2016. str. 64-72.

4. Hoskison E, Grainger J. Fifteen-minute consultation: investigation and management of an infant with stridor. Arch Dis Child Educ Pract Ed 2017; 102(3): 124-6.

5. Ahmad SM, Soliman AMS. Congenital Anomalies of the Larynx. Vol. 40, Otolaryngologic Clinics of North America 2007. str. 177-91.

6. Daniel SJ. The upper airway: Congenital malformations. Vol. 7, Paediatric Respiratory Reviews. 2006

7. Boogaard R, Huijsmans SH, Pijnenburg MWH, Tiddens HAWM, de Jongste JC, Merkus PJFM. Tracheomalacia and bronchomalacia in children: incidence and patient characteristics. Chest 2005; 128(5): 3391-7.

8. Cevik M, Gókdemir MT, Gókdemr MT, Boleken ME, Sogut O, Kurkcuoglu C. The characteristics and outcomes of foreign body ingestion and aspiration in children due to lodged foreign body in the aerodigestive tract. Pediatr Emerg Care 2013; 29(1): 53-7.

9. Brown SGA. Clinical features and severity grading of anaphylaxis. J Allergy Clin Immunol 2004; 114(2): 371-6.

10. Geelhoed G. Croup. In: Encyclopedia of Respiratory Medicine, Four-Volume Set. Elsevier Inc.; 2006. str. 582-4.

11. Lichtor JL, Rodriguez MR, Aaronson NL, Spock T, Goodman TR, Baum ED. Epiglottitis: It hasn't gone away. Anesthesiology 2016; 124(6): 1404-7. 12. Baird SM, Marsh PA, Padiglione A, Trubiano J, Lyons B, Hays A, et al. Review of epiglottitis in the post Haemophilus influenzae type-b vaccine era. Vol. 88, ANZ Journal of Surgery. Blackwell Publishing; 2018. str. 1135-40.

13. Blot $M$, Bonniaud-Blot P, Favrolt N, Bonniaud P, Chavanet P, Piroth L. Update on childhood and adult infectious tracheitis. Vol. 47, Medecine et Maladies Infectieuses. Elsevier Masson SAS; 2017. str. 443-52.

14. Lai SH, Wong KS, Liao SL, Chou YH. Non-infectious epiglottitis in children: two cases report. Int J Pediatr Otorhinolaryngol 2000; 55(1): 57-60. 15. Carter J, Rahbar R, Brigger M, Chan K, Cheng A, Daniel SJ, et al. International Pediatric ORL Group (IPOG) laryngomalacia consensus recommendations. Vol. 86, International Journal of Pediatric Otorhinolaryngology. Elsevier Ireland Ltd; 2016. str. 256-61.

16. Zoumalan R, Maddalozzo J, Holinger LD. Etiology of stridor in infants. Ann Otol Rhinol Laryngol 2007; 116(5): 329-34.

17. Clark CM, Kugler K, Carr MM. Common causes of congenital stridor in infants. Vol. 31, Journal of the American Academy of Physician Assistants. Lippincott Williams and Wilkins; 2018. str. 36-40.

18. Eber E. Evaluation of the upper airway. Vol. 5, Paediatric Respiratory Reviews. W.B. Saunders Ltd; 2004. str. 9-16.

19. Elphick HE, Sherlock P, Foxall G, Simpson EJ, Shiell NA, Primhak RA, et al. Survey of respiratory sounds in infants. Arch Dis Child 2001; 84(1): 35-9. 20. Leung AK, Cho H. Diagnosis of stridor in children. Am Fam Physician 1999; 60(8): 2289-96.

21. Brody AS, Kuhn JP, Seidel FG, Brodsky LS. Airway evaluation in children with use of ultrafast CT: pitfalls and recommendations. Radiology 1991; 178(1): 181-4.

22. Vogl T, Wilimzig C, Bilaniuk LT, Hofmann $U$, Hofmann D, Dresel S, et al. MR imaging in pediatric airway obstruction. J Comput Assist Tomogr; 14(2): 182-6.

23. Filippone M, Narne S, Pettenazzo A, Zacchello F, Baraldi E. Functional approach to infants and young children with noisy breathing: validation of pneumotachography by blinded comparison with bronchoscopy. Am J Respir Crit Care Med 2000; 162(5): 1795-800.

24. Ganie FA, Wani ML, Ahangar AG, Lone GN, Singh S, Lone $H$, et al. The Efficacy of Rigid Bronchoscopy for Foreign Body Aspiration. Bull Emerg trauma 2014; 2(1): 52-4.

25. Eber E, Zach M. [Flexible fiberoptic bronchoscopy in pediatrics--an analysis of 420 examinations]. Wien Klin Wochenschr 1995; 107(8): 246-51.

Petra Pavlič, dr. med.

Služba za pljučne bolezni,

Pediatrična klinika, Univerzitetni klinični center Ljubljana, Ljubljana, Slovenija

Asist. dr. Ana Kotnik Pirš, dr. med. (kontaktna oseba / contact person) Služba za pljučne bolezni,

Pediatrična klinika,

Univerzitetni klinični center Ljubljana,

Ljubljana, Slovenija in

Katedra za pediatrijo,

Medicinska fakulteta, Univerza v Ljubljani, Ljubljana, Slovenija e-naslov: ana.kotnikpirs@kclj.si

prispelo / received: 17. 2. 2020

sprejeto / accepted: 5. 3. 2020

Pavlič P, Kotnik Pirš A. Priporočila za oceno in obravnavo stridorja pri otroku. Slov Pediatr 2020; 27(3): 118-123. https://doi.org/10.38031/ slovpediatr-2020-3-02. 